\title{
Dual Master of Social Work / Master of Public Health Degrees: Perceptions of Graduates and Field Instructors
}

\author{
Trina C. Salm Ward \\ Patricia M. Reeves
}

\begin{abstract}
Despite growing interest in Master of Social Work/Master of Public Health (MSW/MPH) programs, limited research literature is available on MSW/MPH graduates and none has examined field instructors' perceptions of MSW/MPH students. This study describes the perceptions and experiences of MSW/MPH alumni and field instructors from a recently implemented MSW/MPH program at the University of Georgia. Electronic surveys were administered to 32 alumni and 34 field instructors; response rates were $71.9 \%(n=23)$ and $70.6 \%(n=24)$, respectively. Alumni reported satisfaction with the dual degree and utilization of both social work and public health skills in the workplace. Field instructors underscored the complementary skill sets of dually-trained students and noted the added value of MSW/MPH professionals in their agencies. Dually-trained MSW/MPH practitioners are uniquely prepared to address the need for transdisciplinary and interprofessional collaborations to address long-standing social and health issues.
\end{abstract}

Keywords: Public health social work; MSW/MPH: dual degree; joint degree; dual degree programs

Public health social work (PHSW) is a growing profession (Ruth, Marshall, Velásquez, \& Bachman, 2015; Ruth et al., 2008; Ziperstein et al., 2015). While enjoying resurgence in popularity, PHSW actually dates back to the early 20th century when social workers engaged in infectious disease control, maternal and child health promotion, and worked in settlement houses (Popple \& Leighninger, 2004). PHSW practice focuses on: a) promoting health, including disease prevention and protection from environmental dangers, and b) populations rather than individuals (Sable, Schild, \& Hipp, 2012; Watkins, 1985). The knowledge and skills of social workers complement those of public health professionals. Social workers understand the need for tailoring interventions to specific populations, adopt a person-in-environment/family-centered perspective, and provide insight into the social conditions that negatively affect health and health equity (Moniz, 2010; Sable et al., 2012). The knowledge, skills, and values of the two professions coalesce in PHSW and support contributions to research, policy analysis, program development, direct service provision, and administration (Sable et al., 2012).

\section{Need for Collaborative Practice in Social Work}

There is an increased focus on health among social workers. About one-third of social workers practice in health-related settings, with a projected 19\% increase in the need for health care social workers by the year 2024 (U.S. Bureau of Labor Statistics, 2015). The International Federation of Social Workers (2012) calls for an understanding of health,

Trina C. Salm Ward PhD, MSW is an Assistant Professor, Helen Bader School of Social Welfare, University of Wisconsin-Milwaukee, Milwaukee, WI 53211 and formerly Assistant Professor jointly appointed at the School of Social Work and the College of Public Health, The University of Georgia. Patricia M. Reeves is a Professor, School of Social Work, The University of Georgia, Athens, GA 30602. 
asserting "health is an issue of fundamental human rights and social justice and binds social work to apply these principles in policy, education, research, and practice” (p. 1). Moreover, passage of the Affordable Care Act in 2010 has changed the shape of social work practice in health-related settings in the U.S., strengthening focus on improved patient care, reducing costs, and emphasizing prevention as a critical component of health care (Koh \& Sebelius, 2010; Ruth, Marshall et al., 2015). As a result, attention is shifting to interprofessional and transdisciplinary teams to provide health services to meet patient, family, and community health care needs (Haire-Joshu \& McBride, 2013; Koh \& Sebelius, 2010), as evidenced by the creation of the Interprofessional Education Collaborative (IPEC, 2016). The Council on Social Work Education (CSWE) became a member of IPEC in 2014 (CSWE, 2016). Further, long-standing issues of terrorism, disasters, war, disease, viral outbreaks, climate change, oppression, and social justice reinforce the need for creative and multi-perspective problem-solving (Jackson, 2015; Sable et al., 2012).

\section{Added Value of Public Health Education}

Public health education adds tremendous value to an interprofessional partnership with social work. Public health's focus on prevention (primary, secondary, and tertiary) at the population level, coupled with social work's emphasis on intervention at the individual level, ensures a more holistic approach in addressing persistent social problems (McCave, Rishel, \& Morris, 2013; Rine, 2016; Ruth, Velasquez, Marshall, \& Ziperstein, 2015). Underscoring the disciplines' complementary relationship, public health training offers greater inclusion of the biological/physiological aspects of health and well-being which is critically needed to extend the scope of social work education beyond its traditional focus on the psychosocial realm (Andrews, Darnell, McBride, \& Gehlert, 2013; Reisch, 2012; Spitzer \& Davidson, 2013; Ziperstein et al., 2015). Public health education provides skills (e.g., biostatistics, epidemiology, social marketing) that promote a wider range of healthrelated opportunities for students. Public health and social work's shared history, values (e.g., social justice), theory (e.g., ecological), research/evaluation (e.g., community-based participatory), and practice (e.g., interdisciplinary) are strongly aligned (Ashcroft, 2014; Bronstein, Kovacs, \& Vega, 2007; Ruth \& Sisco, 2008; Sable et al., 2012). Students with social work and public health training can apply both perspectives to solving trenchant social and public health issues, and thus address the increased need for transdisciplinary and interprofessional problem-solving (CSWE Commission on Educational Policy \& the Commission on Accreditation, 2015; Haire-Joshu \& McBride, 2013; IPEC, 2016; Koh \& Sebelius, 2010). MSW/MPH students also expand perspectives and conversations in MSW classrooms (Reardon, 2009).

Unquestionably, interest in MSW/MPH degree programs is growing. Over a 30-year period, MSW/MPH programs have maintained high marketability, increasing in number from 20 in 2008 to 42 in 2015 (McClelland, 1985; Ruth, Marshall et al., 2015; Ziperstein et al., 2015). These programs provide a formal integration of knowledge between social work and public health that prepares students to contribute to a dynamic and complex world (Miller, Hopkins, \& Greif, 2008). Students pursue dual degrees for multiple reasons, e.g., a competitive edge in a tight job market, identification with the values of both disciplines, access to the resources (financial, research, course options) of two areas of study, blending 
of the preventive aspect of public health and the problem-solving orientation of social work, and the desire to become a public health social worker (McClelland, 1985; Michael \& Balraj, 2003; Moniz, 2010; Rosenstock, Helsing, \& Rimer, 2011; Ziperstein et al., 2015). Universities may implement dual degree programs in order to increase enrollment or to attract high-quality students, and dual degree programs (vs. serial degree programs) ensure incorporation of the philosophies and concepts of both disciplines (McClelland, 1985).

\section{Limited Literature on MSW/MPH Programs}

Despite the growing interest in and proliferation of MSW/MPH programs, there is a dearth of research literature pertaining to MSW/MPH programs (Miller et al., 2008; Ruth et al., 2008; Ruth, Marshall et al., 2015; Ziperstein et al., 2015). Current literature underscores several challenges for MSW/MPH graduates as they transition to the workplace, including few PHSW role models to demonstrate integration of social work and public health knowledge and skills, limited employer understanding of PHSW, and the perception that dual degree students are over-qualified (Michael \& Balraj, 2003; Ruth et al., 2008). A survey of $153 \mathrm{MSW} / \mathrm{MPH}$ alumni from one long-standing program found that a majority of respondents identified as social workers and held social work licenses (Ruth, Marshall et al., 2015). A majority also reported engaging in core public health functions on a daily or weekly basis, focusing primarily on community mobilization, program evaluation, health promotion, and policy planning/analysis (Ruth, Marshall et al., 2015). While the majority expressed success in integrating public health and social work knowledge and skills, limited employer understanding of PHSW remained a challenge (Ruth, Marshall et al., 2015).

The purpose of this study was to describe and better understand the perceptions and experiences of MSW/MPH alumni and field instructors in a recently-implemented MSW/MPH program in the Southeast. The following questions guided our investigation:

1. How do alumni perceive their preparation by the MSW/MPH program?

2. How are alumni using their MSW/MPH education in the workplace?

3. What are field instructors' perceptions of the preparation and competencies of MSW/MPH students?

The findings reported herein make two important contributions to the literature. First, this study is the first to report data from both graduates and field instructors, and second, it contributes to the limited body of literature on MSW/MPH program outcomes.

\section{Program Overview}

The University of Georgia launched a MSW/MPH program in 2011 through a collaborative partnership between the School of Social Work and the College of Public Health. Based on the challenges identified in the literature and discussions with existing MSW/MPH program coordinators across the U.S., the program was designed with three distinguishing features: a) concurrent social work and public health coursework throughout the program; b) an integrated field practicum that addresses both social work and public health internship requirements; and c) an intensive (seven consecutive semesters, two-anda-half years; many programs are three-year programs), 90-credit program of study. The 
MSW/MPH degree is an option for students in the clinical or community empowerment and program development concentrations in social work and the health promotion and behavior or gerontology concentrations in public health. Students must apply separately to the School of Social Work (MSW program) and the College of Public Health (MPH program) and can enroll at two time points: in fall or spring semester of their first year of graduate study.

The MSW/MPH program is intense, with students typically enrolling in 15 credit hours each semester. MSW/MPH students complete two placements: a one-semester MSW foundation placement and a two-semester integrated social work and public health concentration placement. The integrated placement is completed as a block ( 40 hour/week) placement over the summer, continuing into a 24-hour/week placement in the fall semester of their third year. During the block placement, students integrate public health and social work activities. Field coordinators from both programs work closely together to identify placement sites (e.g., clinics, hospitals, behavioral health clinics) that meet the internship requirements of their respective accrediting bodies and that will offer learning experiences to integrate the knowledge and skills of the two disciplines. Students develop learning plans with objectives, activities, and interventions that will achieve both public health and social work competencies. Assignments during the semester address the competencies of both disciplines. Site visits take place at the beginning and end of the integrated summer semester, with the MSW/MPH program coordinator working in conjunction with field instructors to oversee the integration of the knowledge and skills of both disciplines during the placement.

\section{Methods}

\section{Survey}

The authors developed surveys for each group (alumni and field instructors) based on existing literature (Ruth, Marshall et al., 2015). The surveys included closed- and openended questions. Closed-ended questions used a five-point, Likert-type scale with ratings from 1 (strongly disagree) to 5 (strongly agree). The alumni survey included 51 questions addressing topics such as MSW/MPH program experiences, employment and career experiences, professional identity, and the practice of PHSW. The field instructor survey included 21 questions addressing topics such as perceptions of MSW/MPH student competencies and integration of PHSW in the field experience.

\section{Sampling and Analysis}

As of January 2017, 32 students had graduated from the MSW/MPH program and 34 field instructors had supervised MSW/MPH students during their integrated field placements. Emails with the survey link were sent to all alumni and field instructors inviting them to participate in the survey. Follow-up reminders were emailed at one- and two-week intervals after the initial email. No incentives were provided for participation in the survey and data collection occurred between January and April 2017. The evaluation protocol was reviewed and approved by the university's Institutional Review Board. Descriptive statistics, means, and frequencies were calculated for each of the survey 
questions using SPSS (version 24, IBM Corporation). Open-ended survey responses were reviewed for overarching themes.

\section{Results}

Twenty-three graduates (response rate of 71.9\%) and 24 field instructors (response rate of $70.6 \%$ ) completed surveys. About a third of alumni (39.1\%) had graduated within the previous year and over half (56.5\%) had graduated more than two years ago (see Table 1 ). The majority of alumni (91.3\%) identified as female, White (75\%), and non-Hispanic (81.3\%). Field instructor respondents were almost evenly divided among the four academic years since inception of the program. A little over half (54.2\%) typically supervised both MSW and MPH students, and 45.8\% typically supervised MSW students. Supervisory experience ranged from one to 25 years, with two-thirds (66.7\%) having one to five years of supervisory experience.

\begin{tabular}{|c|c|c|}
\hline Characteristic & $n$ & $\%$ \\
\hline \multicolumn{3}{|l|}{ Graduates $(n=23)$} \\
\hline \multicolumn{3}{|l|}{ Academic Year $(n=23)$} \\
\hline 2013-2014 & 5 & 21.7 \\
\hline 2014-2015 & 8 & 34.8 \\
\hline 2015-2016 & 1 & 4.3 \\
\hline 2016-2017 & 9 & 39.1 \\
\hline \multicolumn{3}{|l|}{ Gender $(n=23)$} \\
\hline Female & 21 & 91.3 \\
\hline Male & 2 & 8.7 \\
\hline \multicolumn{3}{|l|}{$\operatorname{Race}^{\mathrm{i}}(n=16)$} \\
\hline White/Caucasian & 12 & 75.0 \\
\hline Black/African American & 2 & 12.5 \\
\hline Other or mixed race & 2 & 12.5 \\
\hline \multicolumn{3}{|l|}{ Ethnicity $(n=16)$} \\
\hline Not Hispanic & 13 & 81.3 \\
\hline Hispanic & 3 & 18.8 \\
\hline \multicolumn{3}{|l|}{ Field Instructors $(n=24)$} \\
\hline \multicolumn{3}{|l|}{ Academic Year } \\
\hline 2013-2014 & 5 & 20.8 \\
\hline 2014-2015 & 7 & 29.2 \\
\hline 2015-2016 & 6 & 25.0 \\
\hline 2016-2017 & 6 & 25.0 \\
\hline \multicolumn{3}{|l|}{ Students typically supervised } \\
\hline MSW \& MPH students & 13 & 54.2 \\
\hline MSW students & 11 & 45.8 \\
\hline \multicolumn{3}{|l|}{ Supervision experience } \\
\hline $1-5$ years & 16 & 66.7 \\
\hline $6-10$ years & 3 & 12.5 \\
\hline $11-15$ years & 2 & 8.3 \\
\hline $16+$ years & 3 & 12.5 \\
\hline
\end{tabular}




\section{Perceptions of Preparation by the MSW/MPH Program}

When asked about their professional preparation, alumni agreed that they had a strong grasp of social work competencies $(M=4.57, S D=.73)$ and public health competencies $(M=4.52, S D=.51)$, and that they could easily see the connections between social work and public health $(M=4.83, S D=.39$; see Table 2$)$. Respondents reported a good understanding of PHSW that they could describe to others $(M=4.65, S D=.57)$, easily drawing from public health and social work competencies $(M=4.65, S D=.65)$, and seeing problems differently because they had a dual professional perspective $(M=4.83, S D=.39)$. Alumni were satisfied with the decision to pursue a dual degree $(M=4.65, S D=.71)$, and they generally agreed that they felt a part of both public health and social work professions $(M=3.91, S D=1.2)$. In terms of their current employment situation, alumni agreed that their dual degree had a positive impact on their ability to obtain the position $(M=4.45, S D=.69)$.

Table 2. Alumni Perceptions of Preparation $(n=23)$

\begin{tabular}{|c|c|c|}
\hline Survey statement & Mean & $S D$ \\
\hline \multicolumn{3}{|l|}{ I... } \\
\hline have a good grasp of social work competencies. & 4.57 & 73 \\
\hline have a good grasp of public health competencies. & 4.52 & .51 \\
\hline can easily see the connections between social work and public health. & 4.83 & .39 \\
\hline $\begin{array}{l}\text { have a good understanding of public health social work and can describe it } \\
\text { to others. }\end{array}$ & 4.65 & .57 \\
\hline $\begin{array}{l}\text { can easily draw from both public health and social work skills and } \\
\text { competencies. }\end{array}$ & 4.65 & .65 \\
\hline $\begin{array}{l}\text { see problems/issues differently because I have a dual professional } \\
\text { perspective. }\end{array}$ & 4.83 & .39 \\
\hline feel I am part of both public health and social work professions & 3.91 & 1.2 \\
\hline \multicolumn{3}{|l|}{ Program satisfaction } \\
\hline Satisfaction with decision to pursue the dual degree program & 4.65 & .71 \\
\hline \multicolumn{3}{|l|}{ Employment $(n=20)$} \\
\hline MSW/MPH had a positive impact on ability to obtain current position & 4.45 & .69 \\
\hline
\end{tabular}

Overall, the written comments by MSW/MPH alumni were also very positive, focusing mostly on their expanded professional perspective and the marketability of the MSW/MPH degree. For example, alumni described having broader perspectives when approaching social problems:

The dual degree program has provided me with a more well-rounded understanding of human beings and the array of problems in our world today (that need attention from a social work and public health perspective). I believe that social work has provided me with great tools for intervening and working directly and competently with diverse people, while public health has given me a more factbased/science-based approach to improving health outcomes in American society and in other cultures.

It [dual degree program] has allowed me to have more input in my organization's operations. It has given me higher social standing (in some cases) than other social workers. It has given me multiple frameworks to address client health issues and 
organizational challenges. I have research and evaluation skills as well as direct practice competencies, and that has created a niche role for me at my organization.

Most alumni indicated that the MSW/MPH degree increased their marketability and helped them stand out from other candidates, as one noted: "I was told that the reason I got my first job after graduating was because I had two degrees. That put me ahead of other applicants." However, one alumnus expressed doubt about having a competitive edge because of the dual degree, stating, "I think it helped me to meet the minimum requirements for master's-level jobs in these fields, but most jobs only care if I have one degree or the other."

Most alumni also commented on an overall positive learning experience in the MSW/MPH program, including meaningful learning and field placement experiences and positive relationships with advisors. A few, however, expressed frustration with the program having limited options for electives and disappointment with a lack of rigor in the curriculum.

\section{Use of MSW/MPH Education in the Workplace}

The majority (87\%) of alumni were employed at the time of the survey and two (8.7\%) were pursuing doctoral studies (see Tables $3 a$ and $3 b$ ). Slightly less than half of alumni (40\%) worked in a health care setting, followed by government settings (25\%). Alumni reported a variety of position titles, with about half (55\%) requiring a MSW and only one (4.8\%) requiring an MPH. Over half (63.2\%) were earning salaries of $\$ 40,000$ or more. Most respondents (73.9\%) pursued licensure or certifications, with $52.2 \%$ having or pursuing a Licensed Master Social Worker or Licensed Clinical Social Worker credential (Association of Social Work Boards, 2017), followed by the Certified Health Education Specialist (21.7\%) credential (National Commission for Health Education Credentialing, Inc., 2017), and the Certified in Public Health (13\%) credential (National Board of Public Health Examiners, 2017). About a third (34.8\%) of alumni reported belonging to a professional organization, including the National Association of Social Workers (21.7\%), American Public Health Association (4.3\%), or other organizations (21.7\%). Alumni described themselves to others in a variety of ways, including as a social worker (43.5\%), public health social worker (21.7\%), public health professional (8.7\%), health educator $(4.3 \%)$, or by their position title $(13.0 \%)$. Alumni somewhat agreed that they were constrained in their PHSW practice by the limits of their work setting $(M=3.35, S D=1.35)$, that their position was the ideal integration of PHSW $(M=3.35, S D=1.63)$, and that their workplace acknowledged their unique PHSW competencies $(M=4.0, S D=1.26)$. 
Table 3a. Use of MSW/MPH in Workplace $(n=23)$

\begin{tabular}{|c|c|c|c|}
\hline Survey item & & $n$ & $(\%)$ \\
\hline \multirow[t]{3}{*}{ Employment status } & Employed & 20 & 87.0 \\
\hline & Unemployed, looking for work & 1 & 4.3 \\
\hline & PhD student & 2 & 8.7 \\
\hline \multirow[t]{6}{*}{ Type of employer $(n=20)$} & Health care & 8 & 40.0 \\
\hline & Government or other public agency & 5 & 25.0 \\
\hline & Private, not-for-profit agency & 3 & 15.0 \\
\hline & University/research & 2 & 10.0 \\
\hline & Private, for-profit agency & 1 & 5.0 \\
\hline & Self-employed & 1 & 5.0 \\
\hline \multirow[t]{6}{*}{ Position titles $(n=19)$} & Coordinator/specialist, health department & 5 & 26.3 \\
\hline & Medical social worker & 5 & 26.3 \\
\hline & Social worker/behavioral health provider & 3 & 15.8 \\
\hline & Clinical specialist & 2 & 10.5 \\
\hline & Executive director & 2 & 10.5 \\
\hline & Other & 2 & 10.5 \\
\hline \multirow[t]{2}{*}{ Degree required } & MPH $(n=21)$ & 1 & 4.8 \\
\hline & MSW $(n=20)$ & 11 & 55.0 \\
\hline \multirow[t]{4}{*}{ Salary range $(n=19)$} & $<\$ 30,000$ & 1 & 5.3 \\
\hline & $31,000-40,000$ & 6 & 31.6 \\
\hline & $41,000-50,000$ & 9 & 47.4 \\
\hline & $>\$ 50,000$ & 3 & 15.8 \\
\hline \multirow{4}{*}{$\begin{array}{l}\text { Uses the following } \\
\text { competencies }(n=20) \text { : }\end{array}$} & Both social work and public health & 15 & 75.0 \\
\hline & Social work only & 2 & 10.0 \\
\hline & Public health only & 1 & 5.0 \\
\hline & Neither set of competencies & 2 & 8.7 \\
\hline \multirow[t]{4}{*}{ Licensure/certification $^{\mathrm{i}}$} & LMSW, LCSW or applying & 12 & 52.2 \\
\hline & CHES or applying & 5 & 21.7 \\
\hline & $\mathrm{CPH}$ & 3 & 13.0 \\
\hline & None & 6 & 26.1 \\
\hline \multirow[t]{6}{*}{ Self-description } & Social worker & 10 & 43.5 \\
\hline & Public health social worker & 5 & 21.7 \\
\hline & Public health professional & 2 & 8.7 \\
\hline & Health educator & 1 & 4.3 \\
\hline & By position title & 3 & 13.0 \\
\hline & Other & 2 & 8.7 \\
\hline \multirow[t]{4}{*}{ Professional organizations ${ }^{\text {ii }}$} & National Association of Social Workers & 5 & 21.7 \\
\hline & American Public Health Association & 1 & 4.3 \\
\hline & Other & 5 & 21.7 \\
\hline & None & 15 & 65.2 \\
\hline
\end{tabular}

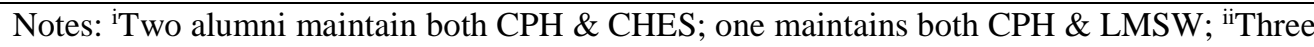
alumni were members of more than one professional organization 
Table 3b. Use of MSW/MPH in Workplace $(n=23)$

\begin{tabular}{lrr} 
Survey statements $(\mathbf{n}=\mathbf{2 0})$ & Mean & SD \\
I am constrained in my public health social work practice by the limits of my & 3.35 & 1.35 \\
$\quad$ work setting. & 3.35 & 1.63 \\
$\begin{array}{l}\text { My position is the ideal integration of public health social work. } \\
\begin{array}{l}\text { My workplace acknowledges/understands my unique public health social work } \\
\text { competencies. }\end{array}\end{array}$ & 4.00 & 1.26 \\
\hline
\end{tabular}

The majority of alumni (75\%) reported using both social work and public health skills and competencies in their position. Alumni were asked to describe the public health and social work skills they used in their workplace settings; of those who responded ( $n=15)$, all listed both public health and social work skills, regardless of position title or profession. Table 4 summarizes the five most commonly cited public health and social work skills, with program design and planning the top skill in public health and assessment and counseling the most often used skills in social work. It should be noted that more social work skills were mentioned, which may reflect the greater number of alumni employed in social work-related positions.

Table 4. Top Five Public Health and Social Work Skills Used $(n=15)$

\begin{tabular}{lll}
\hline Skill & $\boldsymbol{n}$ & $\mathbf{\%}$ \\
\hline Public health & & \\
$\quad$ Program design/planning & 6 & 40.0 \\
Health education & 5 & 33.3 \\
Program evaluation & 5 & 33.3 \\
Health/healthcare policy & 3 & 20.0 \\
$\quad$ Health promotion & 3 & 20.0 \\
Social work & & \\
Assessment & 8 & 53.3 \\
Counseling skills & 8 & 53.3 \\
$\quad$ Case management & 5 & 33.3 \\
$\quad$ Diagnostic criteria & 5 & 33.3 \\
Therapeutic techniques & 4 & 26.7 \\
\hline
\end{tabular}

\section{Perceptions of Field Instructors}

Field instructors agreed that MSW/MPH students evidenced a good grasp of social work competencies $(M=4.67, S D=.48)$ and public health competencies $(M=4.46, S D=.59)$, and demonstrated understanding of social work and public health values $(M=4.79$, $S D=.42)$, theories $(M=4.29, S D=.81)$, and practices $(M=4.54, S D=.59$; Table 5). They agreed that MSW/MPH students were competent to apply for MSW positions ( $M=4.71$, $S D=.69)$ and MPH positions $(M=4.58, S D=.58)$, and that they would hire an MSW/MPH graduate if given the opportunity $(M=4.75, S D=.53)$. Field instructors also agreed that their agency effectively integrated both the MSW and MPH field experience $(M=4.63, S D=.50)$. Supervising a MSW/MPH student also helped field instructors learn how social work and public health are integrated in practice $(M=4.42, S D=.65)$, and field instructors expressed satisfaction with their decision to supervise MSW/MPH students $(M=4.88, S D=.45)$. All but two field instructors (91.3\%) expressed willingness to supervise another MSW/MPH 
student, with the two who were unwilling citing time constraints. All field instructors (100\%) stated they would recommend this university's MSW/MPH program to other students.

Table 5. Field Instructor Perspectives $(n=24)$

\begin{tabular}{lcc}
\hline Survey statement & Mean & SD \\
\hline MSW MPH students demonstrated... & & \\
social work and public health values & 4.79 & .42 \\
competence to apply to MSW position & 4.71 & .69 \\
good grasp of social work competencies & 4.67 & .48 \\
competence to apply to MPH position & 4.58 & .58 \\
social work and public health practices & 4.54 & .59 \\
good grasp of public health competencies & 4.46 & .59 \\
social work and public health theories & 4.29 & .81 \\
Field placement effectively integrated both MSW and MPH field experience & 4.63 & .50 \\
Would hire a MSW/MPH graduate & 4.75 & .53 \\
Field instructor learned how social work and public health are integrated & 4.42 & .65 \\
How satisfied are you with decision to supervise a MSW MPH student & 4.88 & .45 \\
\hline
\end{tabular}

Written comments by field instructors were very positive overall, with most pertaining to the high caliber of the students. Field instructors described them as "motivated," "confident," "outstanding," "ingenious," "self-directed," and "team-oriented." As one stated, "Dual degree students appear to be extremely self-motivated, self-directed, and confident when they arrive at the field placement. They are eager to jump right in.” Field instructors also commented on the added value to the agency in hiring dual degree students, especially in comparison to MSW-only students. They noted, in particular, the stronger skill sets of dual degree students in conducting literature reviews, program development and evaluation, grant and accreditation management, and prevention and physical health. The following statement by one field instructor captured a common sentiment: "Our dual degree intern provided a perspective that was not formerly represented in this organization, so the public health perspective was innovative and valuable. The intern was taken more seriously by administration (MBAs and MDs) at least partly due to the intern's ability to speak a language they understand better than 'MSW talk.'”

Field instructors also noted that the benefits of having MSW/MPH students in comparison to MPH-only students. One, for example, indicated that MSW/MPH students were "better equipped to manage social barriers to medical care." Several remarked that MSW/MPH students were a better fit for their agency's mission. As one expressed, "they can see the larger needs of a population and where they fit in the community, to the more specific work of helping clients connect with those resources they need.”

Additionally, field instructors reported a very positive perception of MSW/MPH students and believed their dual degrees would enhance their marketability. They also offered suggestions for improving the MSW/MPH integrated field experience including providing greater clarity for students about expectations prior to entering the field placement, modifying the timing and length of the integrated field placement (for example, 
three semesters instead of two), and coordinating MSW and MPH field evaluation paperwork.

\section{Discussion}

Despite growing interest in MSW/MPH programs, limited literature exists that describes how alumni from these programs practice PHSW (Ruth, Marshall et al., 2015; Ziperstein et al., 2015) and, to our knowledge, no literature exists on field instructors' perceptions of MSW/MPH students' competencies when completing their field placement experience. The purpose of this study was to describe the perceptions and experiences of MSW/MPH alumni and field instructors associated with a recently implemented MSW/MPH program at the University of Georgia. We found that overall, MSW/MPH alumni were satisfied with their experiences in the program, were employed in PHSW settings, and used both social work and public health skills in their workplace. Field instructors were impressed with MSW/MPH students' performance in the field placement, and saw the added value of dual degree professionals in their agency settings.

Our findings add weight to those found by others. For example, the majority of alumni used both social work and public health skills and competencies in their current employment as well as agreed or strongly agreed that their position is the ideal integration of public health and social work (Ruth, Marshall et al., 2015). As Ruth and colleaguesnoted, our respondents tended to identify more strongly with the profession of social work, calling themselves social workers or public health social workers, and about half pursued social work licensure. Alumni reported success in grasping public health and social work competencies, felt a part of both professions, believed their dual degree had a positive impact on their ability to obtain their current position, and reported satisfaction with their decision to pursue a dual degree.

Previous literature has suggested that the workplace may not fully appreciate the competencies of MSW/MPH practitioners (Ruth, Marshall et al., 2015). We found that our alumni were more likely to agree that practice as PHSW professionals was constrained by the limits of their work setting, and less likely to agree that their position was the ideal integration of PHSW and that their workplace acknowledged their unique PHSW competencies. Nevertheless, our MSW/MPH alumni still found opportunities to apply both social work and public health competencies in their work settings.

Field instructors were very positive in regard to MSW/MPH students' preparation for entering the field and their demonstration of social work and public health competencies. The majority strongly agreed that their agency was able to effectively integrate both MSW and MPH field experiences, which supports the call in the research literature for transdisciplinary and interprofessional perspectives to address current societal problems (Haire-Joshu \& McBride, 2013; Koh \& Sebelius, 2010). Supervising MSW/MPH students also helped field instructors learn more about how social work and public health are integrated in practice. Field instructors clearly appreciated the promise of MSW/MPH practitioners, which seems somewhat in contrast to the perception of MSW/MPH alumni of less understanding of the value of PHSW in their workplace. Prior to student placement in field and to help bolster their willingness to take a MSW/MPH student (with his/her 
unique field requirements), the program's public health and social work field coordinators emphasized to field instructors the value of MSW/MPH students. Thus, field instructors in our sample may have had a more thorough understanding of what MSW/MPH students could offer to an agency. Further, MSW/MPH students work with their field instructors to create learning plans that explicitly describe public health and social work competencies. Perhaps this added orientation helped foster positive field instructor expectations.

MSW/MPH graduates would be well-advised to explicitly describe (both written and verbally) their PHSW competencies to prospective employers as a way to increase awareness of the knowledge and skills they would bring to the workplace setting, and to have continued conversations about how those PHSW competencies can benefit the agency moving forward. Unfortunately, however, as indicated in extant literature and as our findings confirm, a large majority of positions specifically seek an MSW- or MPHprepared practitioner; very few specify both. Thus, it is incumbent for MSW/MPH graduates to advocate strongly for themselves, and to make a compelling case for how their broader, transdisciplinary, and interprofessional perspective on societal problems can benefit the workplace. Most encouraging, as our study and others have shown, is that MSW/MPH graduates understand and can clearly describe the affordances of being dually educated and trained in public health and social work.

\section{Limitations}

This study has some limitations. As the first systematic attempt to collect evaluation data from a newly-implemented program, the sample size is relatively small. However, the literature on MSW/MPH programs suggests that most programs are quite small, graduating an average of seven individuals per year (Ziperstein et al., 2015). Also, the findings are limited to alumni and field instructors associated with one MSW/MPH program, which, as noted earlier, has three distinguishing structural features; thus, the results may not be generalized to other MSW/MPH programs. A further limitation is that gender and racial/ethnic data were not collected from field instructors. Additionally, there is a potential for bias as the authors evaluated their own program. We attempted to minimize this bias by assuring students survey data were anonymous, survey participation (or nonparticipation) would not affect program participation, and by presenting both positive and negative data and comments. Despite these limitations, this study adds to the literature on the perceptions and experiences of MSW/MPH practitioners and adds those of field instructors who have supervised MSW/MPH students, thereby contributing to a broader understanding of MSW/MPH practitioners in real-world settings.

\section{Implications}

Health is a growing area of focus in the social work profession, as is the need for transdisciplinary and interprofessional collaborations to address long-standing social and health issues. Dually-trained MSW/MPH practitioners are uniquely prepared to address such issues. Additional research is needed to gain a more nuanced understanding of the experiences and unique contributions of MSW/MPH practitioners. A national, crossprogram evaluation could help identify common challenges across programs as well as the unique structural strengths of each program (Michael \& Balraj, 2003; Ruth et al., 2008). 
Such feedback would help programs best tailor the educational experience of MSW/MPH students for maximum benefit.

Further, there is a strong need for MSW/MPH practitioners to advocate for how their dual education and training uniquely positions them to address intractable social and health problems. At the individual level, for example, they must confidently and explicitly describe their unique set of PHSW competencies to potential and current employers, and at the macro/policy level, they must engage in advocacy and education. Others have called for cross-school leadership, enhanced resources, a greater investment of faculty time, more student funding, expanded career services, and postgraduate professional education to help maximize the ability of MSW/MPH professionals to apply transdisciplinary approaches to problem-solving, with the long-term result of improved community health (Ruth, Marshall et al., 2015). We enthusiastically support this call. Two potential professional resources for MSW/MPH practitioners are the Public Health Social Work section of the American Public Health Association, and the Health practice area of the National Association of Social Workers.

\section{References}

Andrews, C. M., Darnell, J. S., McBride, T. D., \& Gehlert, S. (2013). Social work and implementation of the Affordable Care Act. Health \& Social Work, 38(2), 67-71. https://doi.org/10.1093/hsw/hlt002

Ashcroft, R. (2014). An evaluation of the public health paradigm: A view of social work. Social Work in Public Health, 29(6), 606-615. https://doi.org/10.1080/19371918.2014.893856

Association of Social Work Boards. (2017). Association of Social Work Boards. Retrieved from www.aswb.org

Bronstein, L., Kovacs, P., \& Vega, A. (2007). Goodness of fit: Social work education and practice in health care. Social Work in Health Care, 45(2), 59-76. https://doi.org/10.1300/J010v45n02_04

Council on Social Work Education [CSWE]. (2016). CSWE among newest members of interprofessional education collaborative. Retrieved from http://www.cswe.org/News/Press-Room/Press-Release-Archives/CSWE-AmongNewest-Members-of-Interprofessional-Edu

CSWE Commission on Educational Policy \& the Commission on Accreditation. (2015). Educational policy and accreditation standards for baccalaureate and master's social work programs. CSWE.

Haire-Joshu, D., \& McBride, T. D. (Eds.). (2013). Transdisciplinary public health: Research, education \& practice. San Francisco, CA: Jossey-Bass.

International Federation of Social Workers. (2012). Health policy statement. Retrieved from http://ifsw.org/policies/health/

Interprofessional Education Collaborative (IPEC). (2016). Core competencies for interprofessional collaborative practice: 2016 update. Washington, DC: IPEC. 
Jackson, K. (2015, November/December). Public health social work: Now more than ever. Social Work Today, 15(6), 12-15.

Koh, H. K., \& Sebelius, K. G. (2010). Promoting prevention through the Affordable Care Act. New England Journal of Medicine, 363, 1296-1299. https://doi.org/10.1056/NEJMp1008560

McCave, E. L., Rishel, C. W., \& Morris, M. (2013). Prevention as an explicit part of the social work profession: Part two of a systematic investigation. Advances in Social Work, 14(2), 544-555.

McClelland, R. (1985). Joint degrees: Do they strengthen or weaken the profession? Journal of Social Work Education, 21(1), 20-26.

Michael, S. O., \& Balraj, L. (2003). Higher education institutional collaboration: An analysis of models of joint degree programs. Journal of Higher Education Policy and Management, 25(2), 131-145. https://doi.org/10.1080/1360080032000122615

Miller, S. E., Hopkins, K. M., \& Greif, G. L. (2008). Dual degree social work programs: Where are the programs and where are the graduates? Advances in Social Work, 9(1), 29-43.

Moniz, C. (2010). Social work and the social determinants of health perspective: A good fit. Health \& Social Work, 35(4), 310-313. https://doi.org/10.1093/hsw/35.4.310

National Board of Public Health Examiners. (2017). National Board of Public Health examiners. Retrieved from www.nbhe.org

National Commission for Health Education Credentialing, Inc. (2017). National Commission for Health Education Credentialing. Retrieved from www.nchec.org

Popple, P. R., \& Leighninger, L. (2004). Social work, social welfare and American society. Boston, MA: Allyn \& Bacon.

Reardon, C. (2009, September/October). Dual degree programs - connecting social work with other disciplines. Social Work Today, 9(5), 16-18.

Reisch, M. (2012). The challenges of health care reform for hospital social work in the United States. Social Work in Health Care, 51(10), 873-893. https://doi.org/10.1080/00981389.2012.721492

Rine, C. M. (2016). Social determinants of health: Grand challenges in social work's future. Health \& Social Work, 41(3), 143-145. https://doi.org/10.1093/hsw/hlw028

Rosenstock, L., Helsing, K., \& Rimer, B. K. (2011). Public health education in the United States: Then and now. Public Health Reviews, 33(1), 39-65. https://doi.org/10.1007/BF03391620

Ruth, B. J., Marshall, J. W., Velásquez, E. E. M., \& Bachman, S. S. (2015). Educating public health social work professionals: Results from an MSW/MPH program outcomes study. Journal of Social Work Education, 51(1), 186-194. 
Ruth, B. J., \& Sisco, S. (2008). Public health social work. In T. Mizrahi, \& L. E. Davis (Eds.), Encyclopedia of social work (20th ed.). Oxford: Oxford University Press.

Ruth, B. J., Sisco, S., Wyatt, J., Bethke, C., Bachman, S. S., \& Piper, T. M. (2008). Public health and social work: Training dual professionals for the contemporary workplace. Public Health Reports, 123(Suppl 2), 71-77. https://doi.org/10.1177/00333549081230S210

Ruth, B. J., Velasquez, E. E., Marshall, J. W., \& Ziperstein, D. (2015). Shaping the future of prevention in social work: An analysis of the professional literature from 2000 through 2010. Social Work, 60(2), 126-134. https://doi.org/10.1093/sw/swu060

Sable, M. R., Schild, D. R., \& Hipp, J. A. (2012). Public health and social work. In S. Gehlert, \& T. Browne (Eds.), Handbook of health social work (2nd ed., pp. 64-99). Hoboken, NJ: Wiley.

Spitzer, W. J., \& Davidson, K. W. (2013). Future trends in health and health care: Implications for social work practice in an aging society. Social Work in Health Care, 52(10), 959-986. https://doi.org/10.1080/00981389.2013.834028

Watkins, E. L. (1985). The conceptual base for public health social work. In A. Gitterman, R. B. Black \& F. Stein (Eds.), Public health social work in maternal and child health: A forward plan. Proceedings of the working conference of the public health social work advisory committee for the bureau of health care delivery and assistance. (pp. 17-33). Rockville, MD: Division of Maternal and Child Health.

U. S. Bureau of Labor Statistics. (2015). Social workers. Retrieved from http://www.bls.gov/ooh/community-and-social-service/social-workers.htm

Ziperstein, D., Ruth, B. J., Clement, A., Wyatt Marshall, J., Wachman, M., \& Velasquez, E. (2015). Mapping dual degree programs in social work and public health: Results from a national survey. Advances in Social Work, 16(2), 406-421. https://doi.org/10.18060/18372

Author note: Address correspondence to: Trina C. Salm Ward, PhD, MSW, Helen Bader School of Social Welfare, University of Wisconsin-Milwaukee, 2400 E Hartford Ave, Milwaukee, WI 53211. Salmward@uwm.edu

Acknowledgement: The authors gratefully acknowledge the willingness of the MSW/MPH graduates and field instructors who enthusiastically shared their viewpoints and opinions. The authors also deeply appreciate the efforts of Kelly Ryder, Prashikshya Karki, Elaina Schreckenberger, and Taylor Kennedy--MSW/MPH students who assisted in literature searches and data collection. 